\title{
LA INTERVENCIÓ DEL PROGRAMA D'EDUCACIÓ COMPENSATÒRIA ALS CENTRES EDUCATIUS DE LES COMARQUES TARRAGONINES
}

\author{
Júlia Pardo Rodríguez. Coordinadora del Programa d'Educació Compensatòria \\ a la Delegació de Tarragona
}

Catalunya ha estat tradicionalment una terra d'acollida de població d'altres indrets. Actualment, amb els processos de desenvolupament econòmic que es viuen i la distribució territorial dels recursos de treball, Catalunya té moltes possibilitats de continuar sent un lloc triat per la població que emigra dels països no comunitaris.

Les dificultats amb què aquestes persones es troben al nostre país poden provocar que es generin processos negatius d'incorporació a la societat que els acull. Les raons són diverses: l'aplicació d'una legislació que no els afavoreix, sovint té més de controladora que d'inclusiva; la por al desconegut, tant per part de la població que arriba com per part de la població que els acull; les dificultats provocades per la manca de coneixement de la llengua, els costums, la religió, els recursos i els serveis; la precarietat $\mathrm{i}$ les males condicions de les ocupacions laborals que realitzen i els sistemes d'accés a l'habitatge i la situació de degradació en què aquests es troben.

L'educació té com a missió formar persones que han de viure en una societat. La socialització de cada individu i la realització personal no han de ser antagonistes. Cal que tendim cap a un sistema que s'esforci per saber combinar les virtuts de la integració amb el respecte dels drets i deures individuals.

Un model d'escola inclusiva ha de vetllar per la integració dels grups minoritaris, mobilitzant $i$ implicant els mateixos interessats en el respecte del seu desenvolupament personal, d'una banda, i de l'altra el respecte dels seus trets culturals. Així doncs, és a l'escola on ha de començar l'educació per a una ciutadania conscient $\mathrm{i}$ activa.

Els sistemes educatius han de respondre als reptes de la societat actual, de la informació i el coneixement, en la perspectiva d'un enriquiment continuat i ajustat dels coneixements necessaris, per tal de poder-se moure i fer ús de l'exercici d'una ciutadania adaptada a les exigències del nostre temps.
L'escola ha de potenciar la convivència i la cohesió comunitària, així com promoure l'equitat d'accés i adquisició dels recursos. El pla d'acollida de centre ha de ser un element de lluita contra l'exclusió social, ha de ser també una eina per ajudar els nouvinguts perquè realment formin part de la comunitat escolar, per tal que acabin aquesta etapa amb les mateixes destreses, coneixements i possibilitats que els permetin viure en un territori com a subjectes actius, autònoms i responsables.

\section{Orígens i evolució del Programa d'Educació Com- pensatòria (PEC)}

El Programa d'Educació Compensatòria comença el curs 1983-84 amb el nom de PEMS (Programa Experimental de Marginats Socials) i neix amb uns objectius molt concrets: ajudar els centres en l'escolarització dels alumnes gitanos i dels alumnes amb risc de marginació social.

Fins aleshores una part important dels alumnes d'ètnia gitana estaven escolaritzats en centres especialitzats de concentració, situats en zones suburbials i que tenien, en general, una connotació d'escoles "ghetto". Aquesta situació comença a canviar quan desapareixen les barriades de barraques i les famílies s'instal-len en pisos. Ja no té sentit que els seus fills vagin a escoles especialitzades nascudes arran de la marginació, sinó que és bo que s'escolaritzin en el centre que escullin dins del nou context en què estan situades. Per altra banda, aquest canvi contribuirà a afavorir la convivència entre "paios" i gitanos i els portarà un millor coneixement mutu.

Els alumnes amb risc de marginació social, en general, presenten dificultats en la seva maduració personal, en la seva habituació i en el procés de socialització a causa de la situació sociocultural de la seva família.

Aquestes dificultats afecten, en molt casos, la motivació, el ritme i la continuïtat en l'aprenentatge. Les escoles aleshores d'acció especial havien desenvolupat una gran tasca en aquest camp, però la mateixa qualificació d'escola com d'acció especial comportaria en 


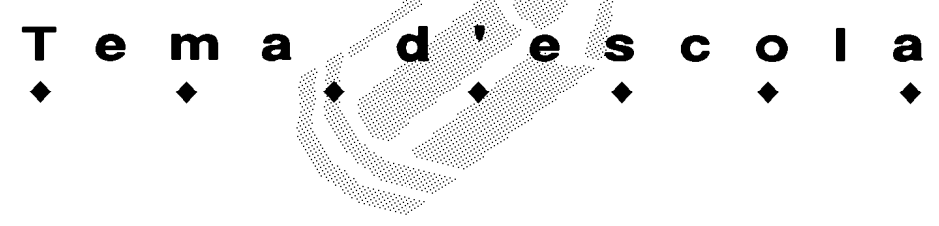

aquells moments una connotació etiquetadora.

Posteriorment les necessitats de les escoles van anar experimentant canvis i també es van ampliar a causa, d'una banda, de la "normalització" dels alumnes gitanos (cada vegada en són més els que comencen l'escola al parvulari, mentre que en els inicis del Programa començaven amb més de vuit anys), i d'altra banda, per l'arribada a Catalunya d'alumnes procedents d'altres països. En aquest sentit el Programa ha ampliat els seus objectius inicials ajudant a aconseguir una normalització escolar dels fills de famílies immigrants. Aquestes vénen majoritàriament del Magrib, en especial del Marroc, i en molt menor nombre d'Algèria i Egipte, també de I'Àfrica centreoccidental: Guinea, el Senegal, Gàmbia o Malí; alguns de Rússia i els països de l'Est Europeu; altres de les Filipines, el Paquistan, Corea o la Xina. Un altre grup, creixent des de fa dos cursos, seria el format pels que consideren "que tornen a casa", els llatinoamericans, en molts casos descendents d'antics emigrants i exiliats espanyols i catalans.

En aquest moment el Programa compta amb 88 professionals. A la demarcació de Tarragona som 8 mestres que atenem totes les comarques de les Delegacions de Tarragona i de les Terres de l'Ebre.

El Programa d'Educació Compensatòria és un programa de suport a la tasca docent dels mestres i dels professors, que té com a finalitat oferir una adequada atenció educativa a centres d'educació infantil i primària i d'educació secundària obligatòria, públics i concertats, a l'alumnat amb necessitats educatives associades a situacions socials o culturals desafavorides, i a l'alumnat pertanyent a minories ètniques o culturals en situació de desavantatge.

Segons el DOG 3242 de 10 d'octubre del 2000: "Correspon al Programa d'Educació l'elaboració de propostes, criteris i actuacions, l'assessorament i el suport als centres en els projectes i les activitats encaminades a la prevenció de qualsevol forma d'exclusió social i a la promoció d'una educació intercultural basada en la igualtat, la solidaritat i el respecte a la diversitat".

\section{Característiques dels alumnes que s'atenen}

El fet de considerar les singularitats dels alumnes que s'atenen és un repte al qual l'escola no pot renunciar, i al mateix temps és un element enriquidor per a tota la comunitat educativa, ja que pot representar un replantejament, un canvi i una millora en moltes actuacions i estratègies que es porten a terme sobre organització escolar, tractament de la disciplina, atenció a la diversitat, treball en valors... En definitiva, introduir innovacions que afecten la millora de la qualitat de l'ensenyament.

D'altra banda, l'escola és un lloc privilegiat per afavorir un conjunt de relacions socials i per treballar a partir de característiques cognitives i afectives diferents.

A causa de la manca de seguretat que en molts casos tenen els alumnes en arribar a l'escola, es procurarà que el primer resultat de la interacció resulti bàsic per a l'actitud que posteriorment prendrà i per a la conducta que reflectirà. En cada cas s'haurà d'aconseguir un equilibri entre drets i deures, possibilitats i exigències, dependència i autonomia, normativa i iniciativa.

Entre algunes de les característiques que presenten els alumnes que atenem, podem destacar:

- Desconeixement de la llengua vehicular de l'escola, sobretot en els alumnes immigrants.

- Valoració diferent de molts aspectes escolars, per desconeixement del seu funcionament.

- Dificultats per assolir uns determinats nivells de competència en les àrees instrumentals, conseqüència d'una escolarització tardana o bé perquè no han estat mai escolaritzats.

- Desconeixement de les nostres pautes culturals, hàbits, ordre, organització del temps i l'espai... diferents de les seves.

- En alguns casos pot haver-hi dificultats del pas d'allò concret a allò abstracte.

- Interès i motivació diversos vers els continguts dels aprenentatges, dificultats de concentració, valoració en uns casos més accentuada dels aspectes orals i poca dels aspectes escrits...

\section{Funcions dels professionals}

- Col-laborar amb els mestres i professors en l'acollida d'alumnes.

- Facilitar criteris sobre escolarització d'alumnes i relació pares-mestres.

- Incorporar estratègies organitzatives que ajudin a atendre les diferents necessitats que presentin aquests alumnes.

- Ajudar a elaborar o facilitar als mestres materials adaptats.

- Col-laborar amb els diferents serveis i programes educatius que intervenen en el centre per tal de proporcionar una atenció específica a aquests alumnes des dels diferents àmbits.

- Oferir informació i orientacions als centres per tal d'incorporar l'educació intercultural al Projecte Educatiu.

- Col-laborar en la gestió d'ajuts econòmics en determinats casos i segons les necessitats que presentin els alumnes.

\section{Actuacions que es porten a terme}

En primer lloc, ajudem a escolaritzar els alumnes 
que pertanyen a minories ètniques i/o amb risc de marginació en els centres, facilitant un suport tècnic, pràctic $i$ orientacions a mestres i professors, de manera que tots els alumnes puguin tenir les màximes possibilitats educatives i desenvolupar les seves potencialitats i el centre, de manera progressiva, sigui capaç de donar resposta a aquesta diversitat social i cultural, potenciant els trets positius de les respectives singularitats. És a dir, atendre el dret a l'educació de qualsevol infant, ser escola per a tots els nens.

Les actuacions en els centres es fan a diversos nivells: famílies, alumnes, tutors i claustres:

- Facilitar orientacions sobre aspectes rellevants per a l'acollida i acceptació del nous alumnes. Els primers contactes d'aquestes famílies i dels mateixos alumnes amb l'escola poden condicionar molt el posterior procés d'escolarització. Les famílies que provenen d'altres cultures tenen un concepte del paper de l'escola diferent del nostre; tanmateix, aquesta desconeix molts aspectes de les seves cultures. Des del PEC es col-labora amb mestres i professors en les actuacions relacionades amb l'acollida dels alumnes.

- Oferir informació i orientacions als mestres sobre aspectes culturals dels alumnes.

- Participar conjuntament amb els tutors en l'observació i detecció de necessitats dels alumnes.

- Facilitar criteris per a la relació amb les famílies.

- Assegurar una adequada relació d'aquests alumnes amb els seus companys.

- Donar suport als centres en l'elaboració del pla d'acollida.

- Col-laborar, conjuntament amb els tutors, si s'escau, en la concreció de determinats aspectes curriculars, amb la finalitat que l'alumne pugui participar al màxim en les activitats que es realitzen a l'aula.

- Participar directament en sessions de classe (suport temporal sempre amb l'acord dels tutors dels alumnes) a fi d'accelerar els aprenentatges dels nous alumnes.

- Establir conjuntament amb el tutor la temporització, criteris d'agrupament, continguts de treball, adaptacions del currículum, si s'escau, criteris d'avaluació i procediments per revisar l'actuació a fi de reduir l'atenció específica.

- Facilitar materials adaptats a les necessitats del alumnes, tenint en compte les activitats del grup classe, evitant que els alumnes facin activitats diferenciades de les de la resta del grup.

- Col-laborar, si cal, en la gestió d'ajuts econòmics per a llibres, material didàctic i menjador escolar.
- Sensibilitzar el centre de la necessitat d'incorporar progressivament l'educació intercultural en el Projecte Educatiu i el Projecte Curricular. Facilitar materials i estratègies d'educació cívica i intercultural (dinàmiques de grups, habilitats socials, convivència, educació per a la democràcia...

- Participar en la promoció i organització d'activitats de formació permanent en l'àmbit de la interculturalitat.

\section{Intervenció als centres}

La intervenció als centres es fa sempre per demanda del mateix centre a l'inspector/a de zona. Les actuacions es concreten cada curs amb la direcció dels centres en un pla de treball on es reflecteixen les activitats que es duran a terme. Es prioritzen aquelles actuacions encaminades a organitzar l'acollida i el seguiment de l'alumnat nouvingut, i elaborar el projecte d'educació cívica i intercultural del centre.

\section{Organitzacio de l'acollida}

Les concrecions de les activitats de cada pla d'acollida estaran en funció del context i de la realitat de cada centre, de les característiques del professorat i de l'alumnat, individuals i de grup, així com de les famílies.

Les condicions escolars de l'alumne i socioeconòmiques de la família poden ser molt diverses, però es planteja necessàriament un procés d'adaptació que es pot facilitar mitjançant unes actuacions d'acollida per tal que els centres puguin assumir els canvis que comporta la interacció cultural amb alumnes procedents d'altres països, i alhora aconseguir que els nous alumnes comprenguin el funcionament del centre i es vagin adaptant juntament amb els companys i el professorat.

Respecte de les famílies, cal tenir en compte que s'ha d'informar les famílies nouvingudes del funcionament i l'organització de l'escola o institut. Cal tenir present que no tots els alumnes han tingut una escolarització prèvia i continuada, i que les pautes culturals i les expectatives que tenen envers l'escola varien molt d'una família a una altra. Molt sovint el que nosaltres considerem manca de participació o despreocupació no és altra cosa que desconeixement, a vegades por, o fins i tot respecte per l'escola.

Pel que fa als alumnes, cal ser conscients de l'esforç personal i intel-lectual que els suposa haver d'entendre les nostres demandes, els nostres codis... Partir de la base que l'alumne "sap" coses i que està capacitat per aprendre més continguts dels que de vegades pressuposem. És important manifestar expectatives positives.

Es procurarà que l'acolliment sigui càlid i afectuós $i$ que tingui continuïtat. 


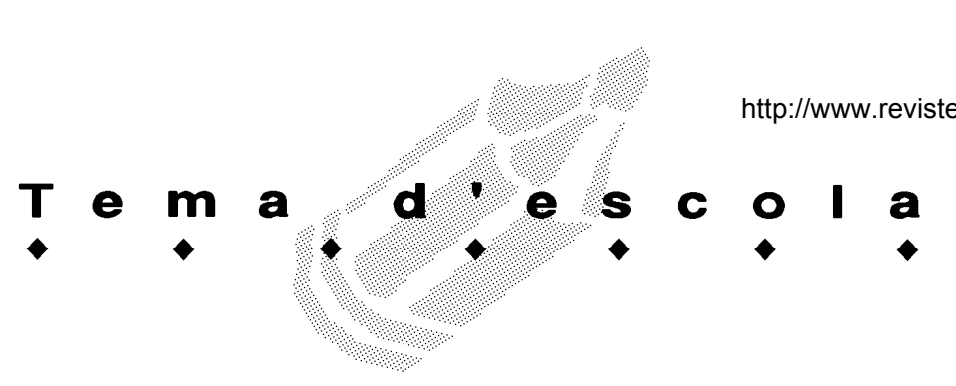

Quan ens adrecem a tot el grup, cal assegurar-nos que quan parlem ens escolta; que se li ha de parlar directament, encara que no ens entengui; que cal vocalitzar bé i parlar a poc a poc; que s'ha d'utilitzar suport visual sempre que sigui possible i utilitzar codis gestuals, si convé; que s'ha de facilitar la seva participació com més aviat millor; que cal potenciar activitats on es treballi la llengua oral i que impliquin comunicació i relació amb els companys i que s'ha de mostrar comprensió i reforçament positiu envers els progressos, encara que siguin molt minsos.

\section{Actuacions concretes}

\section{Avaluació inicial}

És imprescindible realitzar una avaluació i observació inicial per tal de conèixer el seu nivell, especialment en les àrees instrumentals. Aquesta avaluació ens permetrà planificar el seu itinerari escolar.

Organització del currículum a curt termini. Activitats i materials

A partir de la seva escolarització anterior i dels resultats de l'avaluació inicial, cal marcar uns objectius a assolir en períodes curts, per exemple quinzenalment, i planificar activitats reforçades amb materials manipulatius, visuals, auditius i altres.

Atenció personalitzada / recursos humans i materials

L'organització general del centre haurà de preveure amb certa flexibilitat l'atenció individualitzada estructurant i optimitzant els recursos.

\section{Horaris}

Elaboració de l'horari individual on es contemplin les hores de treball individualitzat, on les fa, amb qui i les activitats que farà amb el grup classe.

Organització i funcionament de la classe

És important que el tutor plantegi estratègies que comportin la col-laboració de tots els alumnes. Estratègies que repercutiran positivament en la relació que s'estableix entre tots els alumnes:

- Compartir amb l'alumne nouvingut algun càrrec de la classe.

- Ser el referent per al nou alumne davant de qualsevol dificultat quotidiana.

- Ajudar-lo en activitats concretes d'aprenentatge, dins o fora de l'aula.

- Acompanyar-lo, tenir-lo present a les hores de pati, a les entrades, sortides...

Altres estratègies més globals poden ser la de planificar activitats per donar a conèixer la seva cultura al grup classe, per exemple:

- Escriure el nom dels companys en la seva llengua.

- Llegir un text i comparar les diferències, fer jocs...

- Muntar un racó amb fotografies de diferents països, textos en diferents llengües, salutacions...

- Coordinació entre els diferents professors que intervenen.

La responsabilitat del seguiment del procés d'aprenentatge de cada alumne és del tutor. És imprescindible mantenir reunions periòdiques amb els diferents professionals que hi intervenen per poder valorar el seu progrés i així replantejar metodologies, continguts i materials, així com els ajustaments curriculars necessaris.

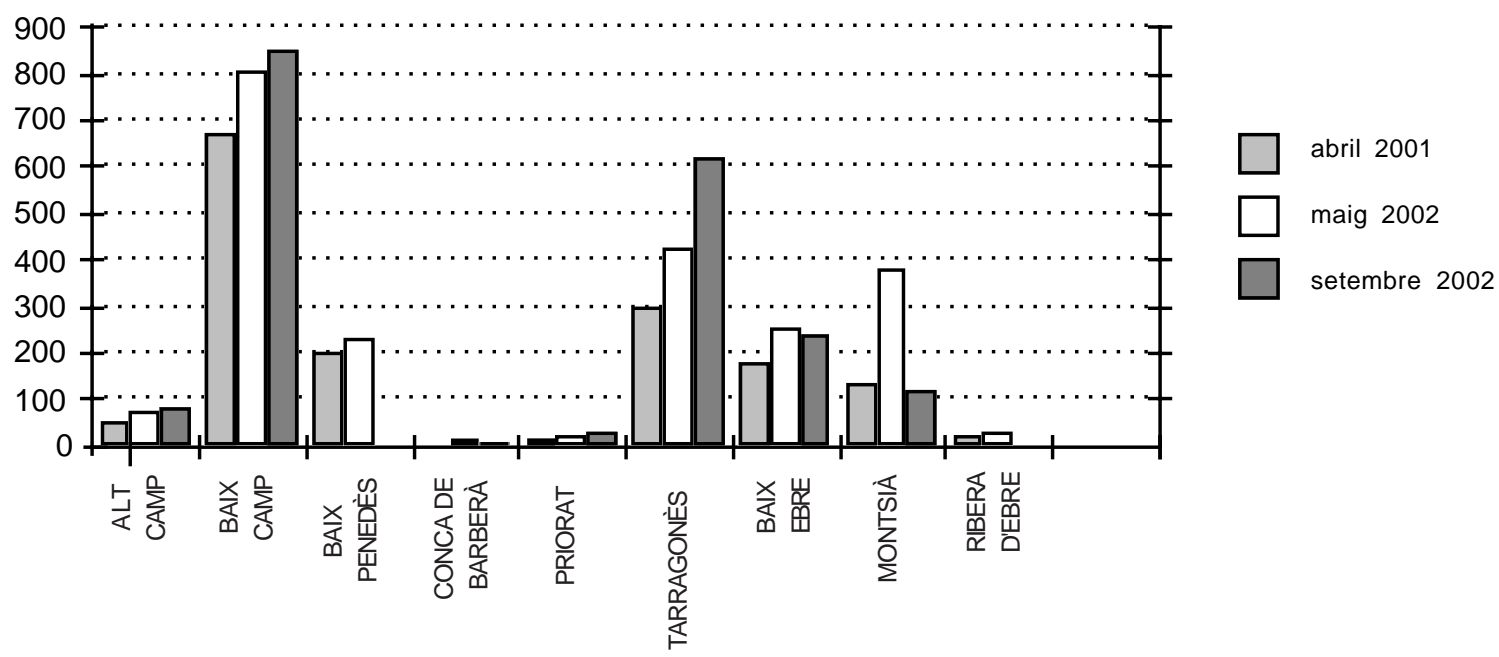

Fig. 1. Evolució de l'alumnat estranger, de procedència diversa, a l'educació primària 


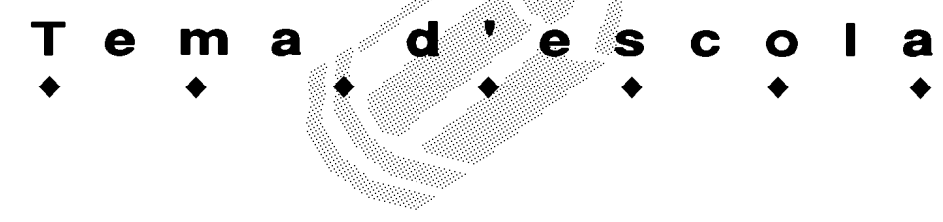

\section{Educació cívica intercultural}

Justificació

L'educació intercultural ha de preparar tots els individus per:

- Viure en societats multiculturals, per avançar cap a un model de societat intercultural.

- fonamentar el respecte i la crítica de totes les cultures.

- consolidar el principi de l'intercanvi i comunicació per sobre de la potenciació de les diferències.

- Afavorir el rebuig actiu del racisme i la xenofòbia.

Objectius

- Cultivar actituds interculturals: potenciar el que ens fa iguals; acceptar i respectar l'altre; admetre i respectar altres models culturals; valorar altres cultures; empatitzar amb valors, creences... d'altres patrons culturals; superar els prejudicis i els estereotips; desenvolupar el sentit crític constructiu i identificar-se d'una manera oberta amb la comunitat cultural pròpia.

- Millorar l'autoconcepte dels alumnes: acollir i acceptar tots els alumnes; assegurar la seguretat afectiva; ressaltar els punts forts i valuosos de la personalitat dels alumnes; reconèixer els progressos acadèmics; incentivar la participació escolar i introduir elements culturals de les comunitats originàries.

- Potenciar la convivència i la cooperació: descobrir el màxim de semblances culturals; incentivar aprenentatges de tipus cooperatiu; perseguir la integració socioafectiva; capacitar per resoldre conflictes; desenvolupar les habilitats socials; acceptar les normes fonamentals de convivència.

- Perseguir la igualtat d'oportunitats: perseguir l'èxit escolar de tots els alumnes; trencar amb les discontinuïtats culturals; planificar concrecions curriculars per respondre a la diversitat; facilitar recursos i estratègies per als aprenentatges; manifestar expectatives positives i realistes respecte de la possibilitat de tots els alumnes d'aconseguir l'èxit escolar.

A les comarques de Tarragona aquest curs es dóna atenció a 130 centres d'educació primària i secundària.

En els darrers dos cursos s'ha produït un increment considerable d'alumnat estranger de procedència diversa, amb un degoteig constant al llarg de tot el curs, principalment en les poblacions més grans. A les figures 1 i 2 es poden comprovar les dades concretes, pel que fa referència a l'evolució d'aquest alumnat estranger, a l'educació primària i a la secundària.

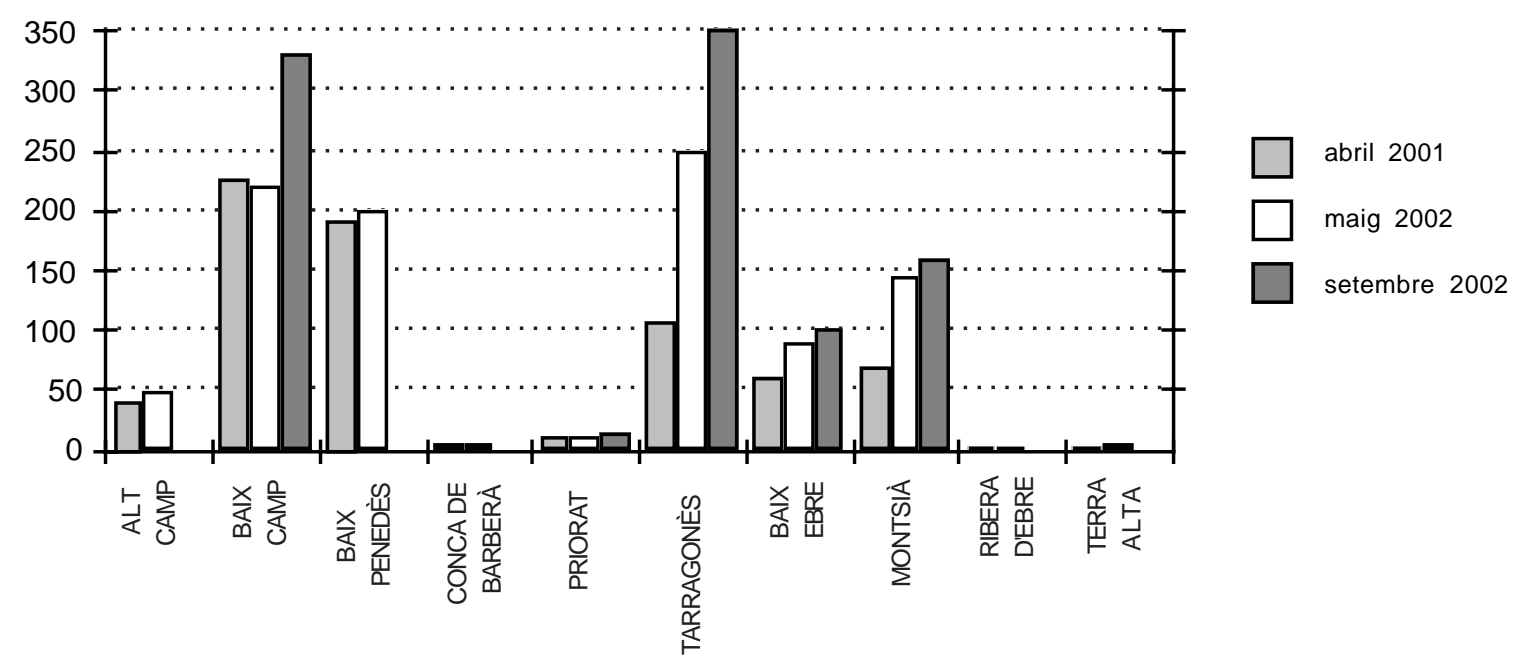

Fig. 2. Evolució de l'alumnat estranger, de procedència diversa, a l'educació secundària 